\title{
Seleção de bactérias degradadoras de petróleo extraídas da rizosfera de Echinochloa polystachya (Kunth) Hitchc.
}

\author{
Selection of oil degrading bacteria extracted from the rhizosphere of Echinochloa \\ polystachya (Kunth) Hitchc.
}

\author{
Suellyn Homan'(*) \\ Agnes Levandowski \\ Leila Teresinha Maranho ${ }^{3}$
}

\section{Resumo}

O petróleo trata-se da maior matriz energética mundial, sendo amplamente explorado e, por este motivo, são frequentes acidentes, derramamentos e vazamentos, em que o mesmo entra em contato com o ambiente. Como consequência, são geradas contaminações do solo e da água, afetando, sobretudo, os animais, as plantas e, principalmente, o homem. Diante dessa problemática, torna-se necessário o desenvolvimento de técnicas de remediação que possam degradar ou reduzir os contaminantes presentes no ambiente. Neste sentido, a presente pesquisa tem como objetivo selecionar bactérias com potencial de degradação de petróleo, extraídas da rizosfera de Echinochloa polystachya (Kunth) Hitchc., Poaceae, espécie nativa de terras inundáveis. Experimentos preliminares com esta planta demonstraram sua tolerância a solos contaminados com petróleo e seu potencial fitorremediador. Porém, constatou-se que este processo é intermediado por micro-organismos associados à sua rizosfera. Devido a esse fato, cinco bactérias foram extraídas da rizosfera desta planta, as quais foram caracterizadas morfologicamente por meio de Coloração de Gram, testadas quanto à produção de biossurfactante e analisadas quanto à degradação de petróleo por meio de testes qualitativos e Cromatografia a Gás (CG). As cinco bactérias são Gram-positivas e apresentam diferentes morfologias, sendo três cocos, um estreptobacilo e um estreptococo. Nos testes qualitativos e na CG, todas demonstraram ser promissoras para a degradação de petróleo. Destas, quatro apresentam

1 Mes.; Biotecnologia Industrial; Universidade Positivo, POSITIVO, Brasil; Professora da disciplina de Ciências para os anos iniciais do Ensino Fundamental e auxiliar de laboratório para os anos finais do Ensino Fundamental; E-mail:

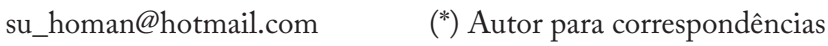

3 Dra.; Engenharia Florestal; Universidade Federal do Paraná, UFPR, Brasil; Professora atuante na Universidade Positivo; Endereço: Universidade Positivo. Rua Prof. Pedro Viriato Parigot de Souza, 5300, Campo Comprido. CEP: 81820-330 - Curitiba, PR - Brasil; E-mail: leila.maranho@pq.cnpq.br 
capacidade de produção de biossurfactante. Estes resultados proporcionaram a seleção de bactérias nativas extraídas de solo contaminado, capazes de degradar petróleo e produzir biossurfactante, podendo ser utilizadas em processos de biorremediação.

Palavras-chave: poluição; petroderivados; tratamento; rizodegradação; biorremediação.

\section{Abstract}

The petroleum is the world's largest energy matrix. In this situation, oil is widely exploited and, therefore, are frequent accidents, spills and leaks, where the oil comes in contact with the environment. This generates contamination of soil and water, affecting above all the animals, plants and especially the man. With this, it is necessary to develop remediation techniques that can degrade or reduce contaminants in the environment. In this sense, the present study aims to select bacteria with potential degradation of oil, extracted from the rhizosphere of Echinochloa polystachya (Kunth) Hitchc., Poaceae, native specie of floodplain environments. Preliminary experiments with this plant showed their tolerance contaminated with oil and their phytoremediation potential soils. However, it was found that this process is mediated by microorganisms associated with its rhizosphere. Five bacteria were extracted from the rhizosphere of this plant, these were characterized morphologically by Gram stain, tested for biosurfactant production and analyzed for degradation of oil by means of qualitative tests and Gas Chromatography (GC). The five bacteria are Gram-positive and exhibit different morphologies, three coconuts a streptobacillus and streptococcus. In qualitative tests and GC, all have proved to be promising for oil degradation. Of these, four have production capacity of biosurfactant. These results provide a selection of native bacteria extracted from contaminated soil, capable of degrading oil and produce biosurfactant, can be used in bioremediation processes.

Key words: pollution; derived from petroleum; treatment; rizodegradation; bioremediation.

\section{Introdução}

O petróleo, composto originado de grandes deposições fósseis, trata-se de uma mistura heterogênea, formada predominantemente por hidrocarbonetos, saturados e aromáticos, e por uma fração polar, asfaltenos e resinas (GAYLARD et al., 1999; VAN HAMME et al., 2003). Levou milhões de anos para ser formado nas rochas sedimentares e constitui a principal matriz energética mundial (GAYLARD et al., 1999; ANDRADE et al., 2010).

Devido à crescente necessidade energética, o petróleo é amplamente explorado, sendo comuns acidentes em que este composto entra em contato com o ambiente. Derrames acidentais, vazamentos em tubulações, uso generalizado e eliminação inadequada de resíduos de petróleo são fontes contínuas de contaminação do solo e de águas subterrâneas (FINOTTI; CAICEDO, 2001; GUEDES et al., 2010). Esta situação afeta diretamente a saúde pública, as comunidades vegetais e animais e, por fim, os ecossistemas como um todo (MARANHO et al., 2006, GUEDES et al., 2010). Por este motivo, o desenvolvimento de pesquisas relacionadas à contaminação dos solos por petróleo e seus derivados cresceu consideravelmente (AGUIAR et al., 2012). 
Diante deste problema, surge a necessidade do desenvolvimento de tecnologias eficientes e de baixo custo que possam descontaminar os solos por meio da diminuição na concentração e/ ou toxicidade dos contaminantes (CUNNINGHAM et al., 1996; FARIAS et al., 2009; RIZZO et al., 2007; GUEDES et al., 2010). As tecnologias empregadas estão relacionadas à remediação térmica, em que são utilizadas temperaturas extremamente elevadas que destroem todos os contaminantes, porém também destroem o solo (AMRO, 2004; TERRATHERM, 2003). Outro método utilizado é a lavagem do solo contaminado, em que o solo é removido e lavado com uma solução contendo solventes leves, com o objetivo de separar as partículas maiores contaminadas do solo não contaminado (MOHANTY et al., 2013). São ainda, comercializadas, a altos custos, almofadas esteiras padrão utilizadas para a limpeza de ambientes onde houve um derrame de petróleo (BUYUKKAMACI; KUCUKSELEK, 2007).

Outro método de tratamento utilizado é a fitorremediação, que utiliza sistemas vegetais para recuperar solos contaminados por poluentes orgânicos ou inorgânicos (CUNNINGHAM et al., 1996), tais como: metais tóxicos (HALL, 2002; WONG, 2003), hidrocarbonetos de petróleo (KAIMI, 2006; SICILIANO et al., 2003), bifenilas policloradas (VAN AKE et al., 2010) e trinitrotolueno (TNT) (RYLOTT; BRUCE, 2009). Neste caso, a estratégia empregada pelas plantas é a rizodegradação, ou seja, a planta favorece o crescimento de micro-organismos na rizosfera - região do solo sob influência da presença de raízes, onde ocorre a maior parte das interações entre micro-organismos e plantas (MACEK et al., 2000) - sendo os micro-organismos, os agentes degradadores dos compostos de petróleo (SANTOS et al., 2007; SICILIANO; GERMIDA, 1998), processo conhecido como biorremediação.

As estratégias de biorremediação têm sido amplamente utilizadas desde os meados dos anos 80, devido a sua eficiência e baixo custo para o tratamento de solos contaminados com petróleo e seus derivados (BENTO et al., 2003; DUA et al., 2002; RAHMAN et al., 2002; TSAO et al., 1998) e, em geral, visam aumentar a população microbiana criando condições ambientais favoráveis ao seu desenvolvimento (SILVA et al., 2004). Dessa forma, o emprego de micro-organismos para a biorremediação se destaca como tecnologia exequível e promissora para o tratamento de resíduos tóxicos e para a descontaminação de áreas poluídas (URURAHY et al., 1998; FERRERA-CERRATO et al., 2006).

Deste modo, a hipótese que norteia o desenvolvimento da presente pesquisa é que as bactérias extraídas da rizosfera de Echinochloa polystachya (Kunth) Hitchc., Poaceae, apresentam potencial de degradação de petróleo em solo contaminado, agindo na redução dos contaminantes, transformando-os em subprodutos menos nocivos ao ambiente. Experimentos preliminares com $E$. polystachya em substratos contaminados com diferentes concentrações de petróleo foram conduzidos por Biazão (2012). Essa espécie demonstrou tolerância quando cultivada em solos contaminados com petróleo e, consequente, potencial fitorremediador de petroderivados, processo intermediado por micro-organismos associados à rizosfera que, nesse mesmo estudo, foram extraídos e isolados. Faz-se necessária, porém, a avaliação de cada micro-organismo, individualmente, para identificação de sua eficiência e estratégias na degradação de petróleo.

Nesse contexto, o objetivo dessa pesquisa foi selecionar as bactérias extraídas a partir da rizosfera de E. polystachya com potencial de degradação de petróleo, com a possibilidade de se estocarem micro-organismos úteis e com elevado potencial de degradação. Os resultados obtidos poderão contribuir com o desenvolvimento de um processo ou produto que melhore a eficiência e o desempenho operacional, reduzindo custos, insumos, consumo de energia, geração de resíduos ou poluição relacionados às atividades petrolíferas. 


\section{Materiais e Métodos}

No estudo de Biazão (2012), em que se cultivou E. polystachya, em solo contaminado com diferentes concentrações de petróleo, essa espécie demonstrou-se tolerante e com potencial fitorremediador. A estratégia de fitorremediação é a rizodegradação, em que o processo é intermediado por micro-organismos associados às raízes da planta fitorremediadora.

Nesse mesmo estudo, as Unidades Formadoras de Colônias (UFC), extraídas da rizosfera, foram quantificadas para os diferentes tratamentos com petróleo. Posteriormente, 25 bactérias foram selecionadas e isoladas, das quais cinco constituem o objeto do presente estudo.

\section{Análise e caracterização}

As placas contendo as bactérias foram numeradas (1 a 5) para posterior preparo de lâminas semipermanentes por meio da Coloração de Gram (BORZANI et al., 2001). Com o auxílio de Microscópio Óptico (OLYMPUS CX21), foram realizadas análises para a caracterização da morfologia das bactérias, bem como de suas colônias (identificadas por meio de sua coloração), conforme literatura especializada em microbiologia (COLLE et al., 1996). Posteriormente, através da análise das placas de Petri, contendo Ágar Nutriente (AN) e mantidas na estufa a 36 ${ }^{\circ} \mathrm{C}$, verificou-se o tempo ótimo, bem como os padrões de crescimento das bactérias.

Realizou-se ainda, a análise de densidade óptica (DO) em espectrofotômetro (MOLECULAR DEVICES SPECTRA MAX M3), no comprimento de onda de $610 \mathrm{~nm}$ das diluições $10^{8}$ de todas as bactérias analisadas.

\section{Seleção das bactérias degradadoras de petróleo}

Inicialmente, realizou-se um teste qualitativo, utilizando uma placa de multipoços. Foram usados dois poços para cada bactéria (duplicata). Em cada poço foram adicionados $500 \mu \mathrm{L}$ de Meio Mineral $\left(\mathrm{K}_{2} \mathrm{HPO}_{4}\right.$ - 0,5 g; $\left(\mathrm{NH}_{4}\right) \cdot 2 \mathrm{SO}_{4}-0,5 \mathrm{~g} ; \mathrm{MgSO}_{4} \cdot 7 \mathrm{H}_{2} \mathrm{O}-0,5 \mathrm{~g} ; \mathrm{FeCl}_{2} \cdot 1 \mathrm{H}_{2} \mathrm{O}-10$ $\mathrm{mg} ; \mathrm{MnCl}_{2}$ - 0,1 mg; $\mathrm{ZnSO}_{4}$ - 0,01 mg; $\mathrm{CaCl}_{2}-10 \mathrm{mg} ; 1000 \mathrm{~mL}$ - água destilada), $20 \mu \mathrm{L}$ de petróleo, $50 \mu \mathrm{L}$ do inóculo de bactérias a uma concentração de $10^{8}$ células. $\mathrm{mL}^{-1}$ e $10 \mu \mathrm{L}$ do indicador 2,6-diclorofenol-indofenol (DCPIP) (HANSON et al., 1993). Preparou-se ainda, dois poços controle, os quais não receberam a inoculação de micro-organismos. A placa foi incubada durante 24 horas à temperatura de $30^{\circ} \mathrm{C}$ e a análise foi realizada visualmente.

Para verificação do potencial de degradação de petróleo foram preparados reatores em frascos de Erlenmeyer para os intervalos de tempo 0, 24, 48 e 72 horas para cada bactéria e em triplicata. Foram ainda preparados reatores sem a inoculação de bactérias nos diferentes tempos (controle). Em cada reator foram adicionados $25 \mathrm{~mL}$ de Meio Mineral, 1,0 mL de petróleo e o inóculo de bactérias com uma concentração de $10^{8}$ células. $\mathrm{mL}^{-1}$ (adaptado de MARIANO, 2006). Todos estes frascos foram mantidos sob agitação em Incubadora refrigerada - "shaker" (TECNAL TE-421) em temperatura de $30-36^{\circ} \mathrm{C}$ a $180 \mathrm{rpm}$.

De cada amostra retirada do "shaker", foi extraída uma alíquota de $10 \mathrm{~mL}$ da suspensão, que foi armazenada em tubos de Falcon e centrifugada (CENTRIBIO TDL80-2B), por 10 minutos. $\mathrm{O}$ sobrenadante foi descartado e o líquido resultante foi analisado quanto à temperatura e pH, com auxílio de um pHmetro (ONDA CIENTÍFICA LTDA - TCP01) e absorbância em espectrofotômetro no comprimento de onda de $610 \mathrm{~nm}$. 


\section{Eficiência da degradação de petróleo}

A avaliação da degradação de petróleo foi efetuada por meio da extração e quantificação de hidrocarbonetos totais de petróleo (SCHWAB et al., 1999).

\section{Extração dos hidrocarbonetos}

A avaliação da degradação de petróleo foi realizada para as amostras obtidas em 72 horas, em triplicata, com inóculo e sem inóculo (controle). Em tubos de Falcon, após adição das amostras, foi colocado $1 \mathrm{~g}$ de sulfato de sódio anidro $\left(\mathrm{Na}_{2} \mathrm{SO}_{4}\right)$ e $5 \mathrm{~mL}$ de diclorometano padrão cromatografia. As amostras foram armazenadas em vidros de âmbar até avaliação por cromatografia a gás (SCHWAB et al., 1999).

\section{Avaliação da degradação mediante Cromatografia a Gás (CG)}

Os extratos foram dissolvidos em $50 \mu \mathrm{L}$ de diclorometano e analisados mediante Cromatografia a Gás, utilizando um cromatógrafo de gases (SHIMADZU GC - 2010) e uma coluna capilar HP-5 (5\%-fenil)-metilpolisiloxano (30 m, 0,25 mm i.d., 0,25 $\mu \mathrm{m}$ de espessura). As temperaturas do injetor e detector foram de $250^{\circ} \mathrm{C}$ e $280^{\circ} \mathrm{C}$, respectivamente, e gás hidrogênio foi utilizado como carreador $\left(1,0 \mathrm{~mL} \cdot \mathrm{min}^{-1}\right)$. A temperatura da coluna foi inicialmente ajustada para $70{ }^{\circ} \mathrm{C}(4,0 \mathrm{~min})$ e aumentada até $190{ }^{\circ} \mathrm{C}$ a uma taxa de $20{ }^{\circ} \mathrm{C} \mathrm{min}^{-1}$, e elevada a $250{ }^{\circ} \mathrm{C}$ a 10 ${ }^{\circ} \mathrm{C} \mathrm{min}{ }^{-1}$ e finalmente alcançou os $280{ }^{\circ} \mathrm{C}$ a $30{ }^{\circ} \mathrm{C} \mathrm{min}{ }^{-1}$ temperatura que foi mantida por 10 minutos. Cada composto foi identificado com base em seus tempos de retenção e porcentagem de redução de área.

\section{Avaliação da produção de biossurfactante}

Com o objetivo de avaliar a capacidade das bactérias isoladas em produzir biossurfactante, foi realizado o teste de colapso da gota de petróleo, em que $100 \mu \mathrm{L}$ de cada suspensão padronizada foram inoculados separadamente em uma placa multipoços, antecipadamente preenchidos com $50 \mu \mathrm{L}$ de óleo mineral. Após 1 minuto de reação, o resultado foi determinado visualmente em Microscópio Estereoscópio (ZEISS - STEMI DV4), considerando-se positiva a produção de biossurfactante quando houve colapso da gota de petróleo (JAIN et al., 1991), caracterizando as reações como: fortemente positiva $(+++)$; positiva $(++)$; fracamente positiva (+); e negativa (-).

\section{Análises estatísticas}

Os dados obtidos foram tabulados em planilhas do programa Microsoft Excel 2010 e, posteriormente, para as análises estatísticas, foi utilizado o programa Statistica, versão 10.0. Os dados foram submetidos ao teste de Shapiro-Wilk para verificar sua normalidade e, por fim, foram comparados por meio do teste não paramétrico de Kruskal-Wallis $(\mathrm{H})$, seguido pelo teste de Dunn, a 5\% de probabilidade.

Foram testadas as seguintes hipóteses: se há diferença na degradação de petróleo entre os tempos analisados para cada bactéria; se há diferença na densidade óptica entre os tempos analisados para cada bactéria; se há diferença na temperatura entre os tempos analisados para cada bactéria; e, se há diferença no $\mathrm{pH}$ entre os tempos analisados para cada bactéria.

\section{Resultados e Discussão}

\section{Análise e caracterização}

Das cinco bactérias analisadas por meio da Coloração de Gram, todas são gram-positivas; com relação à morfologia, podem-se observar diferentes formas, sendo três cocos, um estreptobacilo e um estreptococo. O tempo ótimo de crescimento das bactérias variou de 24 a 48 horas. Três 
bactérias apresentaram tempo ótimo de crescimento em 24 horas (bactérias 3, 4 e 5) e duas entre 24 e 48 horas (bactérias 1 e 2). Na análise de densidade óptica, feita com as diluições $10^{8}$, todas as bactérias, quando comparadas entre si, apresentaram valor aproximado de absorbância, como pode ser observado na tabela 1 .

Tabela 1 - Coloração de Gram, caracterização morfológica, tempo ótimo de crescimento (h) e média de densidade óptica (DO) das bactérias isoladas da rizosfera de E. polystachya

\begin{tabular}{cccccc}
\hline Bactérias & Cor das colônias & Gram & Morfologia & Tempo ótimo (h) & DO média \\
\hline 1 & Rosa Claro & Positiva & Coco & $24 / 48$ & 0,046 \\
2 & Amarela & Positiva & Coco & $24 / 48$ & 0,039 \\
3 & Branco & Positiva & Estreptobacilo & 24 & 0,041 \\
4 & Amarelo Leitoso & Positiva & Estreptococo & 24 & 0,047 \\
5 & Mostarda & Positiva & Coco & 24 & 0,039 \\
\hline
\end{tabular}

Seleção das bactérias degradadoras de petróleo

No teste qualitativo para a avaliação das cinco bactérias, quando comparadas ao controle, todas apresentaram uma redução aparente da quantidade de petróleo nos poços (figura 1), sendo possíveis degradadoras em 24 horas, visto que, nesses poços, ocorreu mudança de coloração do DCPIP de azul, estado oxidado, para incolor, estado reduzido, indicando o crescimento das bactérias nesses meios.

Figura 1 - Teste qualitativo para seleção das bactérias degradadoras de petróleo da rizosfera de $E$. polystachya. 1-2A (bactéria 1); 1-2B (bactéria 2); 1-2C (bactéria 3); 3-4A (bactéria 4); 3-4B (bactéria 5); 3-4C (controle)

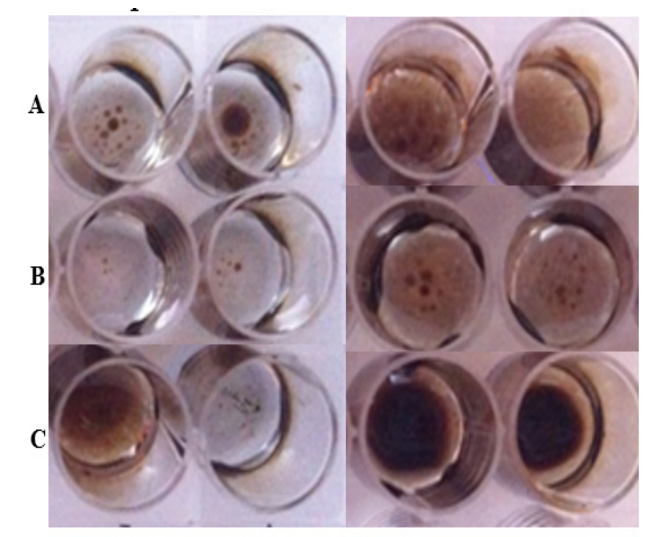

Fonte: Autores (2014).

Com o objetivo de selecionar micro-organismos nativos de sedimentos de manguezais contaminados por petróleo e seus derivados, Fioravanti et al. (2012) utilizaram o mesmo método de placa de multipoços. Obtiveram, como resultado: das 118 cepas de bactérias testadas, 26 são potenciais degradadoras de petróleo em 24 horas, devido à mudança de coloração do meio, de azul para incolor. $\mathrm{O}$ indicador redox DCPIP funciona como um aceptor de elétrons. $\mathrm{O}$ princípio desse teste é a detecção da oxidação da fonte de carbono fornecida às bactérias que, durante o processo de metabolização oxidam o petróleo e os elétrons são liberados no meio (FIORAVANTI et al., 2012; AFUWALE; MODI, 2012). 
Oliveira (2009), utilizando o mesmo método com o objetivo de selecionar micro-organismos endofíticos com capacidade de degradação de petróleo, observou que, das nove bactérias testadas, três apresentaram atividade degradativa em diferentes frações de petróleo, óleo diesel e gasolina, e as demais apresentaram variados perfis. Vale ressaltar que o teste em placa de multipoços, com o indicador DCPIP, constitui um método de baixo custo, podendo ser amplamente utilizado para a seleção de micro-organismos com capacidade de degradar petróleo (AFUWALE; MODI,2012).

No segundo teste para verificação do potencial de degradação de petróleo pelas bactérias, os frascos de Erlenmeyer, aparentemente não apresentaram nenhuma diferença em seu $\mathrm{pH}$, temperatura e padrão de coloração (exceto pela adição de petróleo), desde que foram inoculados até a retirada de cada remessa de testes (em 0,24, 48 e 72 horas), pois foram utilizadas as mesmas condições para todos os reatores.

As análises estatísticas efetuadas também revelaram pouca diferença entre os parâmetros analisados. Como pode ser observado na tabela 2, em relação à densidade óptica (DO) e ao pH, não houve diferença significativa entre os tempos analisados para as cinco bactérias. Já, em relação à temperatura, para a bactéria 2, o tempo 0 foi significativamente superior ao tempo 72 horas. Para a bactéria 3, o tempo 0 foi significativamente superior ao tempo 48 horas e, para a bactéria 4, o tempo 72 horas foi significativamente maior que o tempo 48 horas.

\section{Tabela 2 - Média士desvio padrão de densidade óptica (DO), temperatura (Temp) e pH nos tempos $0,24,48$ e 72 horas para os testes de degradação}

\begin{tabular}{|c|c|c|c|c|c|c|}
\hline \multirow[b]{2}{*}{ Parâmetros } & \multirow[b]{2}{*}{$\underset{\text { (h) }}{\text { Tempo }}$} & \multicolumn{5}{|c|}{ Bactérias } \\
\hline & & 1 & 2 & 3 & 4 & 5 \\
\hline \multirow{4}{*}{ ஜ } & 0 & $0,05 \pm 0,01$ & $0,05 \pm 0,00$ & $0,07 \pm 0,03$ & $0,07 \pm 0,01$ & $0,05 \pm 0,01$ \\
\hline & 24 & $0,08 \pm 0,02$ & $0,08 \pm 0,02$ & $0,10 \pm 0,03$ & $0,05 \pm 0,01$ & $0,07 \pm 0,01$ \\
\hline & 48 & $0,06 \pm 0,02$ & $0,05 \pm 0,02$ & $0,08 \pm 0,04$ & $0,06 \pm 0,02$ & $0,04 \pm 0,02$ \\
\hline & 72 & $0,08 \pm 0,02$ & $0,08 \pm 0,01$ & $0,07 \pm 0,02$ & $0,07 \pm 0,01$ & $0,06 \pm 0,00$ \\
\hline \multirow{4}{*}{ 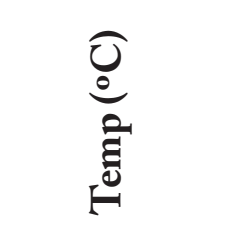 } & 0 & $25,47 \pm 0,67$ & $26,77 \pm 0,25^{\mathrm{a}}$ & $26,70 \pm 0,17^{a}$ & $23,00 \pm 0,62^{\mathrm{ab}}$ & $24,40 \pm 1,66$ \\
\hline & 24 & $21,10 \pm 0,26$ & $25,73 \pm 1,47^{\mathrm{ab}}$ & $25,23 \pm 0,64^{\mathrm{ab}}$ & $24,17 \pm 0,76^{\mathrm{ab}}$ & $22,17 \pm 0,21$ \\
\hline & 48 & $21,50 \pm 0,56$ & $24,97 \pm 0,21^{\mathrm{ab}}$ & $24,10 \pm 0,10^{\mathrm{b}}$ & $22,37 \pm 0,06^{\mathrm{b}}$ & $23,83 \pm 0,95$ \\
\hline & 72 & $22,40 \pm 1,51$ & $23,03 \pm 0,75^{\mathrm{b}}$ & $24,13 \pm 0,21^{\mathrm{ab}}$ & $25,33 \pm 0,29^{\mathrm{a}}$ & $24,13 \pm 0,55$ \\
\hline \multirow{4}{*}{$\frac{\pi}{2}$} & 0 & $6,16 \pm 0,01^{b}$ & $6,57 \pm 0,06$ & $6,43 \pm 0,13$ & $6,88 \pm 0,05$ & $7,28 \pm 0,16$ \\
\hline & 24 & $6,74 \pm 0,03^{a}$ & $6,55 \pm 0,35$ & $6,72 \pm 0,11$ & $6,66 \pm 0,12$ & $6,74 \pm 0,06$ \\
\hline & 48 & $6,62 \pm 0,05^{\mathrm{ab}}$ & $6,65 \pm 0,06$ & $6,67 \pm 0,04$ & $6,63 \pm 0,02$ & $7,11 \pm 0,20$ \\
\hline & 72 & $6,35 \pm 0,18^{\mathrm{ab}}$ & $5,97 \pm 0,23$ & $6,70 \pm 0,03$ & $6,66 \pm 0,04$ & $7,32 \pm 0,11$ \\
\hline
\end{tabular}

*Médias seguidas por letras diferentes indicam diferenças significativa $(p \leq 0,05)$ pelo teste Kruskal-Wallis seguido pelo teste de Dunn. 


\section{Avaliação da degradação mediante Cromatografia a Gás (CG)}

Constatou-se que não houve diferença significativa para a maioria dos parâmetros testados, porém, as análises cromatográficas revelaram eficiência de degradação para todas as bactérias testadas em 72 horas. Para estas, foram constatadas taxas de degradação de 100\% para os 18 compostos com cadeias carbônicas de menor comprimento, quando comparados ao controle, como pode ser observado na figura 2 .

\section{Figura 2 - Perfis cromatográficos do petróleo degradado pelas cinco bactérias testadas em comparação com o controle. A- controle; B- bactéria 1; C- bactéria 2; D- bactéria 3; E- bactéria 4; F- bactéria 5}
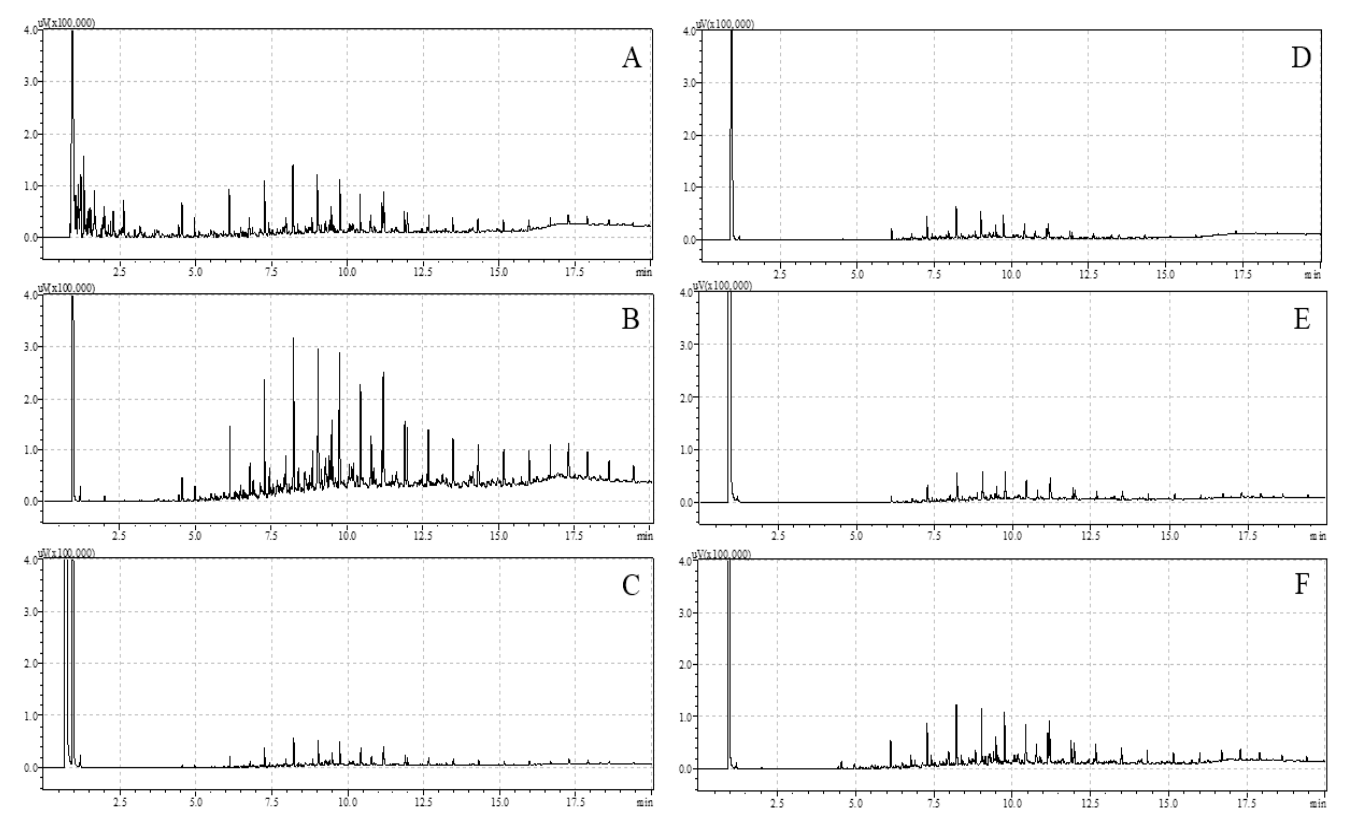

Fonte: Autores (2014).

Para os demais compostos, houve variação significativa nas taxas de degradação. Quatro bactérias (bactérias 3, 6, 7 e 10) demonstraram eficiências elevadas para 14 compostos quando comparadas ao petróleo, entretanto, a bactéria 1 apresentou valores de área superiores aos constatados no petróleo para os cinco últimos compostos, ou seja, sem eficiência de degradação (tabela 3). 


\section{Tabela 3 - Relação de compostos presentes no petróleo puro em comparação com a porcentagem de degradação de petróleo pelas bactérias (1 a 5), extraídas da rizosfera de}

E. polystachya

\begin{tabular}{|c|c|c|c|c|c|c|c|c|c|c|c|}
\hline \multicolumn{2}{|c|}{ Petróleo Puro } & \multicolumn{2}{|c|}{ Bactéria 1} & \multicolumn{2}{|c|}{ Bactéria 2} & \multicolumn{2}{|c|}{ Bactéria 3} & \multicolumn{2}{|c|}{ Bactéria 4} & \multicolumn{2}{|c|}{ Bactéria 5} \\
\hline $\mathbf{T R}^{\mathbf{a}}$ & Área & Área & $\%$ & Área & $\%$ & Área & $\%$ & Área & $\%$ & Área & $\%$ \\
\hline 1,219 & 222725,0 & 31276,1 & 85,96 & 25272,7 & 88,65 & 13389,2 & 93,99 & 14075,6 & 93,68 & $8,783,9$ & 91,57 \\
\hline 1,328 & 205469,1 & 0,0 & 100,0 & 0,0 & 100,0 & 0,0 & 100,0 & 0,0 & 100,0 & 0,0 & 100,0 \\
\hline 1,382 & 43021,7 & 0,0 & 100,0 & 0,0 & & 0,0 & 100,0 & 0,0 & 100,0 & 0,0 & 100,0 \\
\hline 1,418 & 42624,8 & 0,0 & 100,0 & 0,0 & 100,0 & 0,0 & 100,0 & 0,0 & 100,0 & 0,0 & 100,0 \\
\hline 1,478 & & 0,0 & 100,0 & م & & 0,0 & & 0,0 & & 0,0 & 100,0 \\
\hline 1,517 & 8326 & 0,0 & & 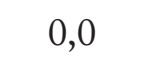 & & 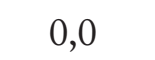 & & 0 & & 0,0 & \\
\hline 1,580 & 7966 & 0,0 & & 0,0 & & 0,0 & & 0,0 & & 0,0 & 100,0 \\
\hline 1,670 & 146290,1 & 0,0 & 100,0 & 0,0 & & 0,0 & & 0,0 & & 0,0 & 100,0 \\
\hline 1,704 & 47250,3 & 0,0 & 100,0 & 0,0 & 100,0 & 0,0 & 100,0 & 0,0 & 100,0 & 0,0 & 100,0 \\
\hline 1,880 & 21317,1 & 0,0 & 100,0 & م & & 0,0 & 0,0 & 0,0 & & 0,0 & 100,0 \\
\hline 1,997 & & 0,0 & & & & & & & & 0,0 & \\
\hline 2,088 & & 15496,0 & & & & & & & & 0,0 & 100,0 \\
\hline 2,135 & 37489,3 & O & & & & & & & & 0,0 & \\
\hline 2,213 & 5422 & 0,0 & 0 & O & 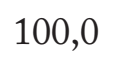 & م م & 1( & 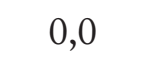 & & 0,0 & 100,0 \\
\hline 2,297 & 101166,4 & 0,0 & 100,0 & 0,0 & 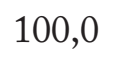 & 0,0 & 100,0 & 0,0 & & 0,0 & 100,0 \\
\hline 2,487 & & 0,0 & & 0 & & 0,0 & & 0,0 & & 0,0 & 100,0 \\
\hline 2,591 & & 0,0 & & & & & & & & 0,0 & 100,0 \\
\hline 2,637 & & 0,0 & & & & & & & & 0,0 & \\
\hline 2,998 & 2207 & & & & & & & & & 0,0 & \\
\hline 3,167 & 6503 & 0,0 & ,0 & & & م مـ & & م0 & & 0,0 & 100,0 \\
\hline 3,220 & 37386,7 & 0,0 &, 0 & 00 & & 0,0 & 100,0 & 0,0 & & 0,0 & 100,0 \\
\hline 3,323 & & 0,0 & & & & & & ; & & 0,0 & 100,0 \\
\hline 3,668 & & & & & & & & & & 0,0 & 0,0 \\
\hline 3,742 & & 20058,6 & & & & & & & & & 83,51 \\
\hline 4,440 & & 22482,6 & 49,81 & & & 4909,1 & & 2708,4 & & 28824,2 & 77,33 \\
\hline 4,559 & 127159,8 & 82677,3 & 34,98 & 911,4 & 92,21 & 35367,0 & 73,64 & 17622,4 & 86,86 & 82633,5 & 38,40 \\
\hline 6,127 & & 240998 & 79,65 & & & & & & & 134314,1 & 15,43 \\
\hline 7,285 & & & & & & & & & & & 4,98 \\
\hline 8,225 & 204337 & 546339 & 167,4 & 96268,9 & 52,89 & 107768 & 35,48 & 128445 & 23,10 & 181730,2 & 8,80 \\
\hline 9,031 & 167034,2 & 614209 & 267,7 & 98197,3 & 41,21 & 69848,7 & 50,87 & 93018,8 & 34,57 & 144902,4 & 1,92 \\
\hline 9,758 & 142166,9 & 444659 & 212,8 & 71418,5 & 49,76 & 47410,4 & 65,31 & 87267,4 & 36,15 & 138220,5 & 1,14 \\
\hline 11,205 & 136665,5 & 451434 & 230,3 & 67578,4 & 50,55 & 13389,2 & 93,99 & 14075,6 & 93,68 & 18783,9 & 91,57 \\
\hline
\end{tabular}

${ }^{a}$ Tempo de retenção.

A Cromatografia a Gás é um método físico-químico de separação dos componentes de uma mistura, por meio de uma fase gasosa móvel por uma fase estacionária solvente, que pode ser líquida ou sólida (AQUINO; NUNES, 2003). Trata-se de um método amplamente utilizado para caracterização e quantificação da composição dos hidrocarbonetos de petróleo, além da confirmação da degradação pela ação de micro-organismos (RAMOS, 2006). 
Linda e Bouziane (2012), em estudo utilizando com as espécies Corynebacterium aquaticum e Pseudomonas aeruginosa, também fazendo uso do meio mineral nas mesmas condições utilizadas no presente estudo e petróleo em diferentes concentrações, obtiveram, através da análise do padrão de degradação por meio de cromatografia gasosa, um percentual de degradação de mais de $75 \%$ em todas as concentrações analisadas, concluindo, dessa forma, que essas espécies podem ser utilizadas em processos de biorremediação de ambientes contaminados com petróleo.

\section{Avaliação da produção de biossurfactante}

Como pode ser observado na tabela 4 , das cinco bactérias testadas quanto à produção de biossurfactante, três foram classificadas como fortemente positivas (bactérias $3,4 \mathrm{e} 5$ ), uma como positiva (bactéria 2) e uma como negativa (bactéria 1).

\section{Tabela 4 - Teste qualitativo de produção de biossurfactante pelas cinco bactérias analisadas}

\begin{tabular}{cc}
\hline Bactérias & $\begin{array}{c}\text { Produção de } \\
\text { biossurfactante }\end{array}$ \\
\hline 1 & $(-)$ \\
2 & $(++)$ \\
3 & $(+++)$ \\
4 & $(+++)$ \\
5 & $(+++)$ \\
Controle & $(-)$ \\
\hline positiva (++): fracamente positiva (+); negativa (-).
\end{tabular}

a fortemente positiva (+++); positiva (++); fracamente positiva (+); negativa (-).

Esses resultados demonstram que $80 \%$ das bactérias analisadas produzem biossurfactante.

Uma das importantes propriedades das bactérias degradadoras de petróleo, presentes na rizosfera é a produção de tensoativos (biossurfactantes). Esses agentes tensoativos são moléculas que reduzem a tensão interfacial e estabilizam a emulsão, aumentando, desse modo, a sua biodisponibilidade, facilitando a degradação de poluentes orgânicos (BANAT et al., 2000; DELEU et al., 1999; LAI et al., 2009).

Silva (2011), com o objetivo de testar as bactérias selecionadas quanto à capacidade de produção de biossurfactantes e utilizando o teste de colapso da gota, observou que, das 112 colônias isoladas, 59 foram capazes de produzir biossurfactante.

Portanto, a presença e a produção dos biossurfactantes confirmam a capacidade de degradação de petróleo, das bactérias extraídas da rizosfera de E. polystachya e selecionadas no presente estudo.

\section{Considerações Finais}

Dessa forma, conclui-se que, das cinco bactérias extraídas da rizosfera de E. polystachya, em relação aos testes qualitativos e através da CG, todas demonstraram-se eficientes quanto à degradação de petróleo, agindo na redução, principalmente, nos compostos de cadeia curta. Dessas, quatro (bactérias 2, 3, 4 e 5) demonstraram a capacidade de produzir biossurfactante. Sugere-se, no entanto, a realização de testes com menores concentrações de petróleo, assim como a identificação molecular das bactérias, de forma que os resultados obtidos constituam 
uma inovação em técnicas envolvendo o processo de biorremediação, visto que as bactérias com elevada eficiência metabólica poderão ser utilizadas para a descontaminação de áreas degradadas ou para o tratamento de resíduos oriundos de processos biotecnológicos.

\section{Agradecimentos}

À Universidade Positivo pela infraestrutura disponibilizada para a realização da pesquisa e, especialmente, à coordenadoria do Curso de Ciências Biológicas.

\section{Referências}

AFUWALE, C.; MODI, H. A. Study of bacterial diversity of crude oil degrading bacteria isolated from crude oil contaminated sites. Lifes Sciences Leaflets, Ahmedabad, v. 6, p. 13-23, 2012.

AGUIAR, C. R. C.; LOPES, B. C.; BARBOSA, M. V. D.; BALIEIRO, F. C.; GOMES, M. M. Fitorremediação de solos contaminados por petróleo. Revista Trópica: Ciências Agrárias e Biológicas, Rio de Janeiro, v. 6, n. 1, p. 03-09, 2012.

AMRO, M. M. Treatment techniques of oil-contaminated soil and water aquifers. International Conference on Water Resources \& Arid Environment, p. 01-11, 2004.

ANDRADE, J. A.; AUGUSTO, F.; JARDIM, I. C. S. F. Biorremediação de solos contaminados por petróleo e seus derivados. Eclética Química, São Paulo, v. 35, n. 3, p. 17- 43, 2010.

AQUINO NETO, F. R.; NUNES, D. S. S. Cromatografia: princípios básicos e técnicas afins. Rio de Janeiro: Interciência, 2003. 188 p.

BANAT, I. M.; MAKKAR, R. S.; CAMEOTRA, S. S. Potential commercial applications of microbial surfactants. Applied Microbiology and Biotechnology, Coleraine, v. 53, n. 5, p. 495-508, 2000.

BENTO, F.M.; CAMARGO, F.A.O.; OKEKE, B.; FRANKENBERGER-JÚNIOR,W. T. Bioremediation of soil contaminated by diesel oil. Brazilian Journal of Microbiology, São Paulo, v. 34, n, 1, p. 65-68, 2003.

BIAZÃO, T. C. Utilização de Echinochloa polystachya (Kunth) Hitchc. (Poaceae) na fitorremediação de solo contaminado com petróleo. 2012. 62 f. Dissertação (Mestrado Profissional) - Universidade Federal do Paraná, Setor de Tecnologia, Programa de PósGraduação em Meio Ambiente Urbano e Industrial, Paraná, 2012.

BORZANI, W.; SCHMIDELL, W.; LIMA, U. A.; AQUARONE, E. Biotecnologia Industrial: Fundamentos, vol. 1. São Paulo: Edgard Blucher, 2001. 288 p. 
BUYUKKAMACI, N.; KUCUKSELEK, E. Improvement of dewatering capacity of a petrochemical sludge. The Journal of Hazardous Materials, Izmir, v. 144, n. 1, p. 323327, 2007.

COLLE, J. G.; FRASER, A. G.; MARMION, B. P.; SIMMONS, A. Practical Medical Microbiology. New York: Churchill Livingstone, 1996. 978 p.

CUNNINGHAM, S. D.; ANDERSON, T. A.; SCHWAB, A. P. Phytoremediation of soils contaminated with organic pollutants. Advances in Agronomy, San Diego, v. 56, n. 1, p. 55-114, 1996.

DELEU, M.; PAQUOT, M.; JACQUES, P.; THONART, P.; ADRIAEN-SEN, Y.; DUFRENE, Y.F. Nanometer scale organization of mixed surfactin/phosphatidylcholine monolayers. Biophysical Journal, Gembloux, v. 77, n. 4, p. 2304-2310, 1999.

DUA, M.; SINGH, A.; SETHUNATHAN, N.; JOHRI, A. K. Biotechnology and bioremediation: successes and limitations. Applied Microbiology and Biotechnology, Delhi, v. 59, n. 1-2, p. 143-152, 2002.

FARIAS, V.; MARANHO, L.T.; VASCONCELOS, E. C.; CARVALHO-FILHO, M. A. S.; LACERDA, L. G.; MENEGASSI-AZEVEDO, J. A.; PANDEY, A.; SOCCOL, C. R. Phytodegradation Potential of Erythrina crista-galli L., Fabaceae, in PetroleumContaminated Soil. Applied Biochemistry and Biotechnology, Curitiba, v. 157, n. 1, p. 10-22, 2009.

FERRERA-CERRATO, R.; ROJAS-AVELIZAPA, N. G.; POGGI-VARALDO, H. M.; ALÁRCON, A.; CAÑIZARES-VILLANUEVA, R. O. Procesos de biorremediación de suelo y agua contaminados por hidrocarburos del petróleo y otros compuestos orgánicos. Revista Latinoamericana de Microbiologia, Montecillo, v. 48, n. 2, p. 179-187, 2006.

FINOTTI, A. R.; CAICEDO, N. O. Contaminações subterrâneas com combustíveis derivados de petróleo: toxicidade e a legislação Brasileira. Revista Brasileira de Recursos Hídricos, Rio Grande do Sul, v. 6, n. 2, p. 29-46, 2001.

FIORAVANTI, K. L.; CELINO, J. J.; ROSSI-ALVA, J. C. Isolamento, seleção e identificação de microorganismos degradadores de petróleo e seus derivados em sedimentos de manguezais contaminados. Cadernos de Geociências, Salvador, v. 9, n. 2, p. 130-141, 2012.

GAYLARD, C. C.; BENTO, F. M.; KELLEY, J. Microbial contamination of stored hydrocarbon fuels and its control. Revista de Microbiologia, São Paulo, v. 30, n. 1, p. 01-10, 1999. 
GUEDES, C. L. B.; CORRER, C. J.; LOBO, I.; ABI-SAAB, O. J. G. Tratamento de solo contaminado com petróleo utilizando tensoativos e peróxido de hidrogênio. Semina: Ciências Exatas e Tecnológicas, Londrina, v. 31, n. 2, p. 87-100, 2010.

HALL, J. L. Cellular mechanism for heavy metal detoxification and tolerance. Journal of Experimental Botany, Southampton, v. 53, n. 366, p. 01-11, 2002.

HANSON, K. G.; DESAI, G.; DESAI, A. J. A rapid and simple screening technique for potential crude oil degrading microorganisms. Biotechnology Techniques, Baroda, v. 7, n. 10, p. 745-748, 1993.

JAIN, D. K.; COLLINS-THOMPSON, D. L.; LEE, H.; TREVORS, J. T. A drop-collapsing test for screening surfactantproducing microorganisms. Journal of Microbiological Methods, Guelph, v. 13, n. 4, p. 271-279, 1991.

KAIMI, E. Ryegrass enhancement of biodegradation in diesel-contaminated soil. Environmental and Experimental Botany, Yokogama, v. 55, n. 1-2, p. 110-119, 2006.

LAI, C.; HUANG, Y. C.; WEI, Y.; CHANG, J. Biosurfactant-enhanced removal of total petroleum hydrocarbons from contaminated soil. Journal of Hazardous Materials, Tainan, v. 167, n. 1-3, p. 609-614, 2009.

LINDA, A.; BOUZIANE, A. Petroleum-oil biodegradation by Corynebacterium aquaticum and Pseudomonas aeruginosa strains isolated from the industrial rejection of the refinery of ARZEW-Algeria. World Applied Sciences Journal, Arzew, v. 18, n. 8, p. 1119-1123, 2012.

MACEK, T.; MACKOVA, M.; KAS, J. Exploitation of plants for the removal of organics in environmental remediation. Biotechnology Advances, Prague, v. 18, n. 1, p. 23-34, 2000.

MARANHO,L.T.; GALVÃO, F.; PREUSSLER, K. H.; MUNIZ, G.I.B.; KUNIYOSHI, Y. S. Efeitos da poluição por petróleo na estrutura da folha de Podocarpus lambertii Klotzschex Endl.,Podocarpaceae. Acta Botânica Brasilica, São Paulo, v. 20, n. 3, p. 615624, 2006.

MARIANO, A. P. Avaliação do potencial de biorremediação de solos e de águas subterrâneas contaminados com óleo diesel.2006.162 f. Tese (Doutorado) - Universidade Estadual Paulista, Instituto de Geociências e Ciências Exatas, Rio Claro, 2006.

MOHANTY, S.; JASMINE, J.; MUKHERJI, S. Practical considerations and challenges involved in surfactant enhanced bioremediation of oil. BioMed Research International, Mumbai, v. 2013, p. 01-16, 2013. 
OLIVEIRA, N. C. Seleção de microrganismos endofíticos com potencialidades para a biorremediação de ambientes contaminados com hidrocarbonetos de petróleo e/ou derivados. 2009. 85 f. Dissertação (Mestrado) - Universidade Federal de Goiás, Instituto de Patologia Tropical e Saúde Pública, Programa de Pós-Graduação em Medicina Tropical, 2009.

RAHMAN, K. S. M.; BANAT, I. M.; THAHIRA, J. Bioremediation of gasoline contaminated soil by a bacterial consortium amended with poultry litter, coir pith and rhamnolipid biosurfactant. Bioresource Technolology, Coleraine, v. 81, n. 1, p. 25-32, 2002.

RAMOS, U. M. Estudo da biodegradação de gasolina por bactérias presentes no solo da área de armazenamento e distribuição de combustíveis no município de Ribeirão Preto. 2006. 76 f. Dissertação (Mestrado) - Curso de Tecnologia Ambiental, Universidade de Ribeirão Preto, 2006.

RIZZO, A. C. L.; LEITE, S. G. F.; SORIANO, A. U.; SANTOS, R. L. C.; SOBRAL, L. G. S. Biorremediação de solos contaminados por petróleo: ênfase no uso de biorreatores - Série Tecnologia Ambiental. Rio de Janeiro: CETEM/MCT, 2007.76 p.

RYLOTT, E. L.; BRUCE, N. C. Plants disarm soil: Engineering plants for the phytoremediation of explosives. Trends Biotechnology, York, v. 27, n. 2, p. 73-81, 2009.

SANTOS, E. A.; SANTOS, J. B.; FERREIRA, L. R.; COSTA, M. D.; SILVA, A. A. Fitoestimulação por Stizolobium aterrimum como processo de remediação de solo contaminado com Trifloxysulfuron-sodium. Planta Daninha, Viçosa, v. 25, n. 2, p. 259265, 2007.

SCHWAB, A. P.; SU, J.; WETZEL, S.; PEKAREK, S.; BANKS, K. M. Extraction of petroleum hydrocarbons from soil by mechanical shaking. Environmental Science \& Technology, West Lafayette, v. 33, n. 11, p. 1940-1945, 1999.

SICILIANO, S.; GERMIDA, J. Mechanisms of phytoremediation: biochemical and ecological interactions between plants and bacteria. Environmental Reviews, Montreal, v. 6, n. 1, p. 65-79, 1998.

SICILIANO, S. D.; GERMIDA, J. J.; BANKS, K.; GREEN, C. W. Changes in microbial community composition and function during a polyaromatic hydrocarbon phytoremediation field trial. Applied Environmental Microbiology, Montreal, v. 69, n. 1, p. 483-489, 2003. 
SILVA, A. M. F. D. Biodegradação de petróleo e produção de biossurfactante por bactérias nativas do sedimento do manguezal de Gargaú, São Francisco do ItabapoanaRJ. 2011.58 f.Monografia (Bacharelado em Ciências Biológicas) - Universidade Estadual do Norte Fluminense Campos dos Goytacazes, Rio de Janeiro, 2011.

SILVA, E.; FIALHO, A.M.; SA-CORREIA, I.; BURNS, R. G.; SHAW, L.J. Combined bioaugmentation and biostimulation to cleanup soil contaminated with high concentrations of atrazine. Environmental Science \& Technology, Lisbon, v. 38, n. 2, p. 632-637, 2004.

TERRATHERM, A. Demonstration of In Situ Thermal Desorption Thermal Blanketsand Wells. TerraTherm Environmental Services, Inc., 01-04, 2003.

TSAO, C.W.; SONG, H. G.; BARTHA, R. Metabolism of benzene, toluene, and xylene hydrocarbons in soil.Applied Environmental Microbiology, New Brunswick, v. 64, n. 12, p. 4924-4929, 1998.

URURAHY,A.F.P.;MARINS,M.D.M.;VITAL, R.L.; GABARDO,I.T.;PEREIRA,J.N. Effect of aeration on biodegradation of petroleum waste. Revistade Microbiologia,São Paulo, v. 29, n. 4, p. 254-258, 1998.

VAN AKE B.; CORREA, P. A.; SCHNOOR,J.L.Phytoremediation of polychlorinated biphenyls: New trends and promises. Environmental Science \& Technology, Philadelphia, v. 44, n. 8, p. 2767-2776, 2010.

VAN HAMME, J. D.; SINGH, A.; WARD, O. P. Recent advances in petroleum microbiology, Microbiology and Molecular Biology Reviews, Kamloops, v. 67, n. 4, p. 503-549, 2003.

WONG, M. H. Ecological restoration of mine degraded soils, with emphasis on metal contaminated soils. Chemosphere, Kowloon Tong, v. 50, n. 6, p. 775-780, 2003. 